\title{
Harmonizing Modern Day Employee Engagement with the Sociological Theory of Symbolic Interactionism
}

\author{
Georgia Simon and Iris Zhou \\ School of Management, Huazhong University of Science and Technology, Wuhan, China
}

\begin{abstract}
Employee Engagement (EE) spans over 30 years discourse within the practitioner and scientific domain, and have become a strategic imperative within organizations. However, due to the tumultuous history of inconsistencies in conceptualization, poor validation, and various discrepancies among scholars and practitioners, the construct has attracted interest across disciplines and industry. Accordingly, the claims of its positive impact on bottom line and other organizational outcome have become the catalyst for further research. Owing to that, this paper highlights past and present findings on EE. Drawing on previous studies, we highlight the cons of the construct and propose a multifoci approach that extends the positive psychology perspective. We reference the earlier works of Kahn, and the influence sociology played in the conceptualization of Kahn's theory of the employee's preferred self. We conclude and recommend the Interactionist view as a theoretical framework within the field of industrial sociology to support our arguments.
\end{abstract}

Key Words: Employee engagement, positive psychology, sociology, rational choice theory, social interactionism

\section{Introduction}

The concept of employee engagement (EE) became popularized after it was first introduced in the seminal work of William Khan in 1990. Khan (1990) defined employee engagement as the "harnessing of organization member selves to their work roles." His conceptualization of the "member self" was influenced by the work of sociologist Erving Goffman from his study of the presentation of "Self" in everyday life (Goffman, 1956), wherein he investigated the different roles of a person's "preferred self" in social interactions, of which he opines as having a significant impact on one's behaviour.

Correspondingly, Khan in his study observing summer camp workers posited that in EE people exhibit discretionary effort in the things that they want to do, by demonstrating that effort in the simultaneous employment and expression of their physical, cognitive and emotional selves during work performances, which promote connections to work and to other personal presence. Since his seminal work, a plethora of studies have emerged with various definitions, and conflicting arguments on the conceptualization, measure and other aspects of EE.

Interestingly, while Khan and Goffman have emphasized the "self" other proponents have demonstrated how the "preferred self" is manifested in EE as "a positive fulfilling state of mind characterized by vigor, dedication and absorption towards one's work and organization" (Schaufeli, Salanova, GonzalezRoma, \& Bakker, 2002). Furthermore, some researchers have opined that EE is an outcome variable, and one that is offered individually by one's own discretion (Wollard \& Shuck, 2011). However, regardless of the different conceptualizations, it is widely accepted that the most overt characteristics of EE is often manifested through energy, enthusiasm, and having interest in one's work, and as such it continues to be a desirable outcome for employees and organizations.

There is no doubt of the consensus between practitioners and academics on the desirable impact of $\mathrm{EE}$ on employee performance, and the attainment of positive organizational outcome. In fact, over the past years, and especially since the after math of the global recession, it has been proven that engaged employee's are the link to maintaining competitive advantage over rivals, and are a catalyst for improving internal and external financial indicators (Gallup, 2010) as well as bringing a positive outcome to organizations (Rigg, 2013).

Corresponding author: Georgia Simon, School of Management, Huazhong University of Science and Technology, Wuhan, China. Email: georgiar_simon@yahoo.com

(c)

This article is distributed under the terms of the Creative Commons Attribution License, which permits unrestricted use and redistribution provided that the original author and source are credited. 
However, the conceptual and validation discrepancies are considered the greatest concern among the proponents of the concept. Correspondingly, the problem exists in the failure to conceptually differentiate $\mathrm{EE}$ from other similar concepts which have caused errors and resulted in inaccurate measure of the underlying mechanisms of the construct in comparison with another (Briner, 2014; Saks \& Gruman, 2014). Notwithstanding these irregularities, there is a consensus on the positive outcome of $\mathrm{EE}$, and if it is not harnessed correctly it can bring about adverse changes in performance, motivation, tremendous loss in revenue, and even more critically a misrepresentation of the concept. In fact, the seriousness of the lack of engagement and the ability to create it has become a global challenge. Correspondingly, a global engagement survey revealed that only $13 \%$ of the world's population is engaged in their work, and US companies spend over 400 billion per year for disengagement (Biro, 2013; Sorenson, 2013, 2016). Given those astounding findings, business leaders have had to galvanize their efforts to stymie the problem of disengagement in a practical way.

The rapid changes brought on by globalization and successive recessions have seen a drastic change in the dynamics of organizations. To this end, organizational or individual outcomes that can be translated into profits, productivity and can maintain competitive advantage have become a major priority (Sorenson, 2013). Employee engagement, is one such priority, and has had a fair share of development in organizational science for the past 3 decades (Crawford, Rich, Buckman, \& Bergeron, 2014). Regardless of this long history, EE has failed to empirically live up to its claims, and as such current scholars are calling for a multi-dimensional and multi-discipline approach to understanding this phenomenon (Bersin, 2014; Saks, 2006; Wollard \& Shuck, 2011). Furthermore, meaningful studies have since highlighted some of the gaps with good reasoning supported by the inadequacies of past studies, and the recommendation that future researchers should examine EE from multiple lenses (Kumar, 2014; Schaufeli, 2014). The title of this paper suggests that we should investigate engagement in a more modern and dynamic way. The underlying significance of this title is in support of the aforementioned views. Undoubtedly, in order to elucidate the idea that EE is a fad or an elusive concept, the old way of defining, measuring and conceptualizing EE needs to be reassessed. The attempts by other scholars to investigate the multi-dimensionality of $\mathrm{EE}$, particularly on the factor of the "self", one's rational choice is often lacking or overlooked by practitioners and scholars. The rational choice, influenced by social interaction can be a pertinent factor which could help to explain why employees engage. It is for this reason that this paper intends to add renewed insight into another possible avenue of social interactionism (SI)

\section{Diversity of Employee Engagement}

In light of the potential risks and the high cost of disengagement, many leaders saw the lack of engagement as a tremendous threat to the bottom line outcomes and productivity (Aon Hewitt, 2013; Towers Watson, 2013). Accordingly, in an effort to understand and create an environment to influence EE, many of the assessments and survey of EE were initiated by consultancy firms which in most cases were specific to the applied settings, and arguably lacked the scientific validity and reliability. Owing to this, various measures and studies abound in an attempt to understand EE, and have contributed to the development of the construct over time. However, there is no doubt on what is known about the drivers, consequences, and outcome of EE. In fact, despite the inadequate and diverse theoretical and empirical nomological propositions, studies including Albrecht (2010; 2014), Hallberg \& Schaufeli (2006), Harter et al. (2002), Maslach, Schaufeli, \& Leiter (2001), Robinson et al. (2004), Schaufeli \& Bakker (2004), Schaufeli et al. (2002), and Schaufeli, Bakker, \& Salanova (2006) have contributed to what we now know; and many others have also contributed to the perpetuation of this unique construct.

Additionally, majority of the previous studies (e.g. Bakker \& Demerouti, 2008; Khan, 1990; Macey \& Schneider, 2008; Maslach et al., 2001) was built on the epistemology of positive psychology. Nonetheless, the contradictions are many, and in order to provide greater elucidation on the construct, others have retired the uni-dimensional approach to theoretically and empirically testing EE, and have embarked upon a multi-dimensional perspective (Saks, 2006). A review of extant literature espouses the need to assess what has been done in an attempt to address the current gaps. Notably, other researchers have supported this view in some way or another (Wefald \& Downey, 2009; Shuck \& Wollard, 2010; Shuck \& Reio, 2014) among a plethora of other studies all aimed at expanding a diversified outlook on the construct.

\section{Linking the measure to understanding the gap}

Consistent reviews have supported and recommended that more needs to be done on EE. However a review of literature pointed that the major flaw in understanding EE, was the uni-focal method of operationalizing $\mathrm{EE}$ as just an outcome variable with little emphasis on the processes before the desired outcome. Furthermore, since EE is seen as a performance-related variable which enhances competitive advantage, especially from an applied perspective, studies have been more 
focused on leveraging the outcomes of EE, instead of isolating and exploring the factors that influence EE (Christian et al., 2011; Macey \& Schneider, 2008). Consequently, this has created unanswered questions and insufficient details about what could be the inherent factor influencing one's discretionary effort. Moreover, this assessment may also be flawed, however, much of this uncertainty was perpetuated from the academic domain as majority of studies on EE were qualitatively done with little collaboration on the lived experiences of employee's or with little practical application within industry.

Moreover, one of the flaws is that many of these qualitative surveys were administered with pre-assigned questions to measure EE. Accordingly, some of the conclusions that were drawn from extant literature have questioned how it has been practically applied, and also how it has been empirically investigated. These have been evidenced to have contributed to the poorly validated measures that existed (Sorenson, 2013; Macey \& Schneider, 2008; Mann \& Harter, 2016; Macey \& Schneider, 20008; Shuck, 2011; Standar \& Rothman, 2010). Furthermore, due to the fact that engagement is an individually offered construct, exhibited by discretionary effort, it cannot be inflated, artificially created, nor demanded (Shuck \& Wollard, 2011). Consequently, many of the pre-designed measures done quantitatively are often lacking in insufficient knowledge of the construct.

In fact, apart from UWES Scale which was developed by Schaufeli and others, and the Gallup Q12 scales (Gallup, 2010; Schaufeli et al., 2002), all other scales have been viewed with scepticism because the scale dimensions are not scaled specifically to factors of engagement but includes measures of satisfaction, motivation and other similar constructs (Schaufeli \& Bakker, 2010; Schaufeli et al., 2008; Viljevac, Cooper-Thomas, \& Saks, 2012). These findings have raised questions regarding the validity and overlap of other similar well established constructs (Wefald, Mills, Smith, \& Downey, 2012).

\section{Engagement and similar constructs}

Markedly, in spite of the inconsistencies that prevail, there has been significant growth in our knowledge of some of the pertinent factors and outcome of EE. Nonetheless, the number of empirical studies has been few and far between, and as such it creates a huge gap. Consequently, due to these shortcomings, there is a need for further investigation. Moreover, some scholars have even expressed that EE is a mare fad and that it is no different from other previous well established constructs such as job satisfaction, commitment, and organizational citizenship behaviour (Macey \&
Schneider, 2008; Saks \& Gruman, 2014; Wollard \& Shuck, 2011), and have deemed this construct as elusive (Castellano, 2015; Witemeyer, 2013). Accordingly, Rigg posited that one of the first steps in bridging the gap, is to understanding the concept and its relationship to other similar concepts, so that it is engagement that is measured and not something else (Rigg, 2013). Additionally, others have opined that due to the complex nature and current diffusion in its conceptualization and measure, EE should just be ignored (Guest, 2014; Purcell, 2014).

On the contrary, many studies have since emerged championing EE as a distinct construct which possess like characteristics to other well established constructs, but have its own unique characteristics (Seppalia, et al., 2009; Schaufeli et al., 2006; Hallberg \& Schaufeli, 2006). Hence, engagement is expressed by vigor, dedication and absorption (Schaufeli et al., 2008), and are also characteristics exhibited by an employee who is satisfied with their job, but it does not mean that EE and Job satisfaction are the same. Even though satisfied employees possess positive emotions towards their jobs, they may not exhibit enthusiasm or high energy as an engaged employee would (Schaufeli, 2014). Furthermore, EE is an expression of an employee's preferred self into his role performances. Therefore, such specifications of EE become more distinct, and can clearly be differentiated from other construct (Macey \& Schneider, 2008). Additionally, given the overlapping definitions within the practitioner and consultancy domain, there is a marked similarity of some key terms, though expressed differently, they all have the same psychological under-pinning; they include, work related state-of-mind (Dvir, Eden, Aviolio, \& Shamir, 2002), enthusiasm and involvement, extra role behaviour (Robinson et al., 2006), psychological state (Macey \& Schneider, 2008), combination of behaviours (Mone \& London, 2010) and multi-dimensional (Schaufeli, 2014; Shuck, 2011). The outcome of these studies is well known within the scholar and practitioner's domain. Although, a great differentiation can be ascertained based on the measure, reliability and construct validity (Schaufeli, 2014), many of the previous studies provided further insight into the construct. Moreover, others have argued about the current use of quantitative measures such as the UWES scale, and scale that are geared towards job or organization engagement being used inter-changeably. In light of this, scholars have criticized the empirical robustness of some of these findings as the scale measure can be a potential discriminant of the expected outcome (Wefald et al., 2012).

Unlike other constructs, EE requires an employee's own discretion, which is intrinsic and distinctive from other work related attitudinal and psychological constructs (Rich, LePine, \& Crawford, 2010). 
Additionally, engagement has been said to be a higher order behavioural construct related to job satisfaction, organizational commitment and job involvement (Newman \& Harrison, 2008). However, regardless of other construct similarities, once there is an absence of the fundamental characteristics of EE driven by the positive psychology (of meaning and purpose) posited by Kahn and others Kahn $(1990,2010)$ they cannot be compared to EE, hence they are not the same.

\section{Dynamic nature and demerits of engagement}

It is commonly known that, EE may have similarities to other constructs and may be influenced by a person(s) or circumstance(s), owing to the individualistic (personal) nature of EE (Davila \& Pina-Ramirez, 2014). Furthermore, the potential exists for one's level of engagement to be temporary, and may fluctuate or change based on situations or environments (Bakker, A. 2014; Fletcher \& Robinson, 2014; Kim \& Kolb, 2013). Despite that, the current research gaps are concerned with determining how and what causes one to be engaged. In light of this, the current review attempts to elucidate the mechanism of the employee's self beyond its current positive psychology foundation. The evidence that human behaviour is not consistent, and drivers of engagement are not permanent, contribute to the difficulties organizations have in sustaining an engaged workforce. Hence, what might be an antecedent (driver) today in a specific context or situation may not be so in another context. Similarly, others have opined that engagement evolves across the organization at multiple levels, and may not be exclusively determined by the employee. According to a global audit of employees from USA, only $43 \%$ of employees are engaged in the workforce, the other percentage is either actively disengaged or not engaged (Towers Watson, 2013). Accordingly, scholars have recommended that organizations should build work experiences that foster engagement (Shuck et al., 2013) as the current rate of engagement globally is disheartening.

\section{Analysis of Theoretical Foundations}

In the absence of a specified theory of engagement, scholars have utilized many of the existing theories within the field of psychology to explain the concept of engagement. The most widely used theory is Social Exchange Theory (SET) and Job Demand Resource Model (JD-R Model). These theories have been nomologically and empirically used to demonstrate the link between various organizational outcomes and employee behavior's (Bakker et al., 2005; Cropanzo \& Mitchell, 2005; Saks, 2006). SET was first introduced in theory by Blau (1964) on the premise of reciprocity between an employer and an employee. The theory was premised on the actions that are contingent on rewarding reactions from others. These exchanges were implied as two-sided and mutually contingent on reciprocity. The principle of the theory was built on the reinforcement of psychology and economics (Homans, 1961). Similarly, we examine the theory of Rational Choice Theory (RCT) as a comparative alternative to explaining how one might employ one's discretionary effort in the case of Employee engagement.

\section{Exploring the Social Interactionism Framework}

The changing workforce brought on by globalization, technological advancement and the changing nature of organization has had far more impact on employees' attitudes and behaviours than we can understand. Accordingly, employees' needs, desires and what drives their motivation are often misunderstood. Consequently, circumstances of reciprocity are becoming less of a motivation for employees to stay committed in their task or organization (Rich et al., 2010). According to a recent study, a considerable amount of today's workforce is made up of millennials, and accordingly, it is said that $38 \%$ are not feeling connected to their organization. Correspondingly, only 40 percent are found to be connected (Mann \& Harter, 2016). In fact, studies have shown that millennials are less concerned about the transactional nature of their jobs, but more about non-financial issues such as the environment and social factors not relating to bottom line (Glavas, 2012; Wrzesniewski, 2003).

It is widely accepted that attitudes are said to be related to behaviours and actions, hence the attitudes of employees towards EE are subjected to various agents of socialization. So far, we know that our concept of work can be seen as a learned behaviour from our early development, as well as our social roles within our organizations (Kahn, 2001; Parsons, 1937; Skinner, 1953). These statements serve to strengthen our theorization and the premise on which we prose that the theory of Rational Choice (RCT) is worth considering in understanding EE. The following explanation utilizes the ontological and epistemological foundations of the theory to correlate with the main mechanism at play in employee engagement.

\section{Theoretical Background and Synthesis}

In light of the foregoing theorization, we argue that SET may be redundant in the context where rewards are not the main driver of engagement. Furthermore, we question if in the absence of an exchange whether employees would exercise their personal discretion by means of Rational Choice to determine why and what to engage in. Rational Choice Theory (RCT) is a social science theory that has its foundations in economics, 
marketing, sociology and in areas of law and political science. Proponents of the theory have often used it in creating a framework around one's personal decision making, and individualism. Owing to that, and its multi-discipline application, it was found that there is a marked correlation between the mechanisms of the theory and that of EE.

Even though SET has been repeatedly used, and in many instances applicable in explaining EE, RCT provides a closer correlation to an employee's "self" interest or "discretionary effort". Correspondingly, RCT emphasizes how and what determines the choice one makes, while SET depends on a situation of mutual gain to influence an employee's behaviour. Furthermore, on the contrary of SET, EE cannot be demanded, inflated or artificially created (Wollard \& Shuck, 2011). Therefore, we argue that a transaction of reciprocity of which forms the basis of the social exchange in SET is not enough to influence an employee's discretionary effort in EE.

In light of this, we will briefly define "discretionary effort" (DE) to justify its similarity to RCT. According to Kahn, DE is defined as involving one's preferred self into their role performances (Kahn, 1990). Other proponents have described it as a specific form of in-role or extra role effort of behaviour (Graber, 2015; Tower-Perrin, 2003), expressed as "going above and beyond, going the extra mile, giving all you've got and many other similar phrases. However, DE is not just about extra role effort or going above and beyond. It is generated from a plethora of intrinsic, extrinsic, internal and external factors which becomes the framework or backbone from which employee decisions are made, regardless of cost or benefit to the individual. Interestingly, though it is influenced by various factors, only the employee can decide why and what to employ their DE (May et al., 2004) which in turn would stimulate their vigour, dedication and absorption to their tasks (Shuck \& Wollard, 2010). In fact, Kahn and others have posited that the more employees' are able to show their whole selves at work, the more likely they will expend discretionary effort and become engaged (Glavas \& Godwin, 2013; Kahn, 1990). RCT is considered a viable model within the fields of economics, marketing, sociology and decision making literature, and practice. Although, we know that EE is driven by various factors, we recognize the significant effect of the employee's "preferred self" and the ability to exercise their DE.

\section{Discussion}

Rational Choice Theory was introduced in literature by George Homans in 1961. The theory has its application in social interactionism (SI) and is defined by how self-interested individuals choose a course of action or behaviour that is most in line with their personal preferences (Green, 2002). Interestingly, though SET has its roots in RCT the dynamics of the theory call for a different kind of conceptualization and application. Arguably, both ideologies are influenced by SI, however the epistemology of either construct defies treating them the same.

Furthermore, SET focuses on social exchanges between organization and employees embedded in reciprocity and social obligation; for example, I give, you give in return. In contrast, RCT occurs whether or not there is reciprocity. In fact, once the situation or decision is favourable for the employee they will be motivated by their self-interest or discretionary effort to make a decision. Coincidentally, we may concur that employees will engage not just because the organization is offering rewards, training or other benefits, instead they will engage because it suits their needs. Additionally, RCT has shown to be free of reciprocal biases which occur in instances where something is being offered in exchange for one's engagement. Accordingly, studies have shown many organizations have relied on antecedents or drivers to influence engagement (Crawford et al., 2014; Macey \& Schneider, 2008). In light of this, EE is often deemed elusive because of the dynamic nature of employee's behaviour, and among other things, what may be the influence to engage today may not be the same tomorrow, as engagement is a temporary state of being (Shuck \& Wollard, 2010).

Chiefly, what makes RCT uniquely related to EE is that it is not influenced by any type of obligation or instigation from the organization. Rather, it occurs solely on the rational and calculative choice of the employee whether influenced by the work environment or other sociological conceptions (Coleman, 1990). Additionally, unlike SET, RCT is generally influenced by desires or goals that are of interest to the employee's preferences (Abbott, 2008). Often, employees are faced with the choices and their choice has to coincide with what is their personal preference in the context of what is presented in that moment or circumstances. Hence, the employee will measure their personal loss/gain and decide which is more feasible, and will give the best outcome (Carling, 1992). Furthermore, in SET Homans opines that "no exchange can continue unless both parties are making a profit or benefitting (Homans, 1961).

Therefore, there is a significant difference between the mechanisms of SET and RCT. In fact, SET is more likely to be perceived by employees as a social obligation than an opportunity to use free will. Surely, employees should want to engage on their own, and not because of intimidation through social exchanges that offer reward or punishments (Homans, 1961). Similarly, in SET employers should also not feel 
punished if they perceive or whether there is actual equity. Comparatively, to how an employee feels when they experience a breach of their psychological contract. It can be argued that the strength of RCT lies in its ability to produce a testable theory (Levi, 1997). However, most notably, is that the comparative mechanisms between rational choice and discretionary effort produce an interrelatedness which can be used to explain EE.

Implication

There is enough evidence from both practitioner and academic literature to conclude that despite over 30 years of research, the concept of EE still requires more rigorous study, and a unified understanding of its meaning. Owing to that, we also believe that the construct could greatly benefit from a greater impact from empirical studies seeking less to finding the meaning, but more to understand the mechanisms involved in causing one to be engaged, as well determining whether we can predict engagement in light of one's rational choice or discretionary effort when there are known or unknown drivers and outcomes.

Furthermore, in light of the changing dynamics within the workplace, we also found that the antecedents of engagement are becoming more complex, and difficult to sustain. Therefore, what may influence engagement today may not be so tomorrow. Additionally, the literature has revealed that over the years much reliance have been placed on the field of psychology to explain the inherent behaviour /attitude expressed by an engaged employee. Therefore, considering the existing gaps in understanding engagement, it would be prudent to make way for other theories to help to elucidate the construct. Moreover, it is widely known that most of the work done on the construct has dominance in the practitioner's field, with a few empirical studies and action research in academia. Owing to this, unless the focus changes the literature will continue to have gaps in the understanding of what Employee Engagement really is.

Additionally, on the basis of these gaps, and diffusion we believe that if a consensus is reached between the two groups on the definition of engagement, there might be more completeness and validation of the construct. Furthermore, subsequent research has strengthened the fact that though EE is similar to other well established construct it is a distinct construct (Shuck, 2010; Macey \& Schneider, 2008). Therefore, what if instead of focusing solely on psychology to explain the cognitive aspect of engagement, we consider how the sociological aspect both internal and external of work may impact one's engagement. Moreover, EE is considered an individual/personal construct and as such a person (employee) can be considered a sum total of both the cognitive (psychology) and social (sociology) self. In light of this, we may consider that a person's internal environment (mental state) and their external environments (work/home) may be influencing an employee's "preferred self" (Goffman, 1961; Kahn, 1990) which may be demonstrated and expressed through one's personal characteristics or trait (Schaufeli et al., 2008). Undoubtedly, this begs for future researchers to investigate the social/ psychological aspects of the "self" as a predictor or determinant of engagement. Finally, a unified meaning is required to eliminate the diffusion within the literature. It is widely known that engagements mean different things to different entities. There is no doubt that a symbiotic relationship could exists between empirical and practical validation, as such future researchers are encouraged to utilize a combination of various disciplines to explain, and justify the underlying mechanisms at play for EE to occur and be sustained.

\section{Conclusion}

Arguably, there is no one theory that can fully explain such a dynamic concept as engagement. Employee engagement is by far one of the most dynamic concepts being explored in organizational behaviour for more than 20 years. The extent to which researchers have analysed, and have sought answers is testament to the sustained interest. Likewise, various answers and suggestions on conceptual and theoretical frameworks will surface. However, literature has revealed that some theories might have lost their appeal or usefulness. So far, SET tends to be too rigid on the laws that govern exchange. Furthermore, these laws or interactions tend to generate obligation. Owing to that fact among other tenets of SET, it contradicts the essence of "discretionary effort" in employee engagement.

There is no doubt that SET has made significant contributions to the understanding of the construct. However, our finds support the theoretical significance of RCT as the foundation of this theory is etched in individualism, which is highly correlated to EE. Markedly, as stated before, there is no one best solution or theory for EE. However, the longer it takes to have consensus on the meaning, conceptualization and measurement of engagement, the longer it will take for us to fully understand the extent to which this distinctiveness can be applied across disciplines, and whether or not the concept has the ability to morph beyond its current state. Despite refuted claims that engagement resembles other well established constructs, the absence of consensus on the meaning, and a validated measure is the less conviction the theories and explanation will have pertaining to the antecedents, and outcome of engagement, hence reducing to a mere fad or an elusive construct. 


\section{References}

Abbott, K. W. (2008). Enriching rational choice institutionalism for the study of international law. University of Illinois Law Review, 2008(1), 5-46.

Albrecht, S. L. (2010). Handbook of employee engagement. Cheltenham: Edward Elgar.

Albrecht, S. L. (2014). A climate for engagement: some theory, models, measures, research, and practical applications. In B. Schneider \& K. Barbera (Eds.), The Oxford Handbook of Organizational Climate and Culture (pp. 400-414). Oxford: Oxford University Press.

Aon Hewitt. (2013). 2013 Trends in Global Employee Engagement. Retrieved May 6, 2017, from http://www.aon.com/attachments/human-capital-consulting/2013_Trends_in_Global_Employee_Engagement_Report.pdf

Bakker, A. B. (2014). Daily fluctuations in work engagement:An overview and current direction. European Psychologist, 19 , 227-236. https://doi.org/10.1027/1016-9040/a000160

Bakker, A. B., \& Demerouti, E. (2008). Towards a model of engagement. Carrier Development International, 13, 209-223.

Bersin, J. (2014). It is time to rethink the employee engagement issue. Retrieved from https://www.forbes.com/forbes/welcome/?toURL=https://www.forbes.com/sites/joshber$\sin / 2014 / 04 / 10 /$ its-time-to-rethink-the-employee-engagement-issue/\&refURL=\&referrer=

Biro, M. (2013). Employee engagement: Every leader's imperative. Retrieved May 6, 2017, from http://www.forbes.com/sites/meghanbiro/2013/05/19/employeeengagement-every-leadersimperative/

Blau, P. M. (1964). Exchange and power in social life. New York: John Wiley \& Sons, Inc.

Briner, R. (2014). What is employee engagement and does it matter? An evidence-based approach. In Engage for Success (The future of engagement: thought piece collection). Retrieved from http://www.cipd.co.uk/HR-resources/research/future-engagement.aspx

Carling, A. (1992). Rational choice and household division. In C. Marsh \& S. Arber (Eds.), Families and households (pp. 106-124). London: Macmillan.

Castellano, W. G. (2015). A new framework of employee engagement.

Christian, M. S., Garza, A. S., \& Slaughter, J. E. (2011). Work engagement: A quantitative review a test of its relations with task and contextual performance. Personal Psychology, 64(1), 89-136.

Coleman, J. S. (1990). Foundations of Social Theory. Cambridge: Press of Havard University.

Crawford, E. R., Rich, B. L., Buckman, B., \& Bergeron, J. (2014). The antecedent and drivers of employee engagement. In C. Truss, K. Alfes, R. Delbridge, A. Shantz, \& E. Soane (Eds.), Employee Engagement in Theory and Practice. (pp. 57-81). London: Routledge.

Cropanzano, R., \& Mitchell, M. S. (2005). Social exchange theory: an interdisciplinary review. Journal of Management, 31 , 874-900.
Dvir, T., Eden, D., Aviolio, J. ., \& Shamir, B. (2002). Impact of transformational leadership on follower development and performance: a field experiment. The Academy of Management Journal, 45, 735-744.

Fletcher, L. and Robinson, D. (2014). Measuring and understanding engagement. In C. Truss, K. Alfes, R. Delbridge, A. Shantz, \& E. Soane (Eds.), Employee Engagement in Theory and Practice (pp. 587-627). London: Routledge.

Glavas, A. (2012). Employee engagement and sustainability: a model for implementing meaningfulness at and in work. Journal Corporate Citizenship, 46, 13-29.

Gallup. (2010). Employee Engagement: What's Your Engagement Ratio? Washington, D.C.

Glavas, A., \& Godwin, L. N. (2013). Is the perception of "goodness" good enough? Exploring the relationship between perceived corporate social responsibility and employee organizational identification. Journal of Business Ethics, 114, 15-27.

Graber, S. (2015). The two sides of employee engagement. Retrieved May 6, 2017, from https://hbr.org/2015/12/the-two-sides-of-employee-engagement

Green, S. L. (2002). Rational choice theory: An overview, 7.

Guest, D. (2014). Employee engagement: fashionable fad or long-term fixture? In C. Truss, R. Delbridge, K. Alfes, A. Shant, \& E. Soanne (Eds.), Employee Engagement in Theory and Practice. Abingdon: Routledge.

Hallberg, U. E., \& Schaufeli, W. B. (2006). "Same same" but different? Can work engagement be discriminated from job involvement and organizational commitment? European Psychologist, 11, 119-127.

Harter, J., Schmidt, F., \& Hayes, T. (2002). Business unit level relationship between employee satisfaction, employee engagement and business outcomes: a metaanalysis. Journal of Applied Psychology, 87, 268-279.

Homans, G. C. (1958). Social behavior: Its elementary forms. American Journal of Sociology, 63, 597-606.

Kahn, W. A. (2001). Holding environments at work. Journal of Applied Behavioural Science, 37(3), 269-279.

Kahn, W. A. (1990). Psychological conditions of personal engagement and disengagement at work. Academy of Management Journal, 33, 692-724.

Kahn, W. A. (2010). The essence of engagement. In S. L. Albrecht (Ed.), Handbook of Employee Engagement: Perspectives, Issues, Research and Practice (pp. 2230). Cheltenham: Edward Elgar.

Kim, W., Kolb, J. A., \& Kim, T. (2013). he relationship between work engagement and performance: A review of empirical literature and a proposed research agenda. Human Resource Development Review, 12, 248-267.

Kumar, V., \& Pansari, A. (2014). Customer need and solution, 1. https://doi.org/10.1007/s40547-013-0006-4

Levi, M. (1997). A model, a method, and a map: Rational choice in comparative and historical analysis. In Comparative politics: rationality, culture and structure (pp. 19-41). Cambridge: Cambridge University press.

Macey, W., \& Schneider, B. (2008). The meaning of employee engagement. Industrial and Organizational Psychology, 1, 3-30.

Mann, A., \& Harter, J. (2016). Worldwide employee engagement crisis. Retrieved May 6, 2017, from 
http://news.gallup.com/businessjournal/188033/worldwide-employee-engagment-crisis.aspx

Markos, S., \& Sridevi, M. S. (2010). Employee engagement: The key to improving performance. International Journal of Business \& Management, 5(12), 89-96.

Maslach, C., Schaufeli, W. B., \& Leiter, M. P. (2001). Job burnout. Annual Review of Psychology, 52, 397-422.

Mone, E. M., \& London, M. (2010). Employee Engagement through Effective Performance Management: A Practical Guide for Managers. New York: Routledge.

Newman, D. A., \& Harrison, D. A. (2008). Been there, bottled that: Are state and behavioural work engagement new and useful constructs "wines"? Industrial and Organizational Psychology, 1, 31-36.

Parsons, T. (1937). The Structure of Social Action. New York: McGraw-Hill.

Purcell, J. (2014). Disengaging from engagement. Human Resource Management Journal, 24, 241-254.

Rich, B. L., LePine, J. A., \& Crawford, E. R. (2010). Job engagement: Antecedents and effects on job performance. Academy of Management Journal, 53, 617635.

Rigg, J. (2013). Worthwhile Concept or Old Wine? A Review of Employee Engagement and Related Constructs. American Journal of Business and Management, 2 (1), 31-32.

Robinson, D., Perryman, S., \& Hayday, S. (2006). The drivers of employee engagement.

Saks, A. M. (2006). Antecedents and consequences of employee engagement. Journal of Managerial Psychology, 21, 600-619.

Saks, A. M., \& Gruman, J. A. (2014). What Do We Really Know About Employee Engagement?. Human Resource Development, 25, 155-182. https://doi.org/10.1002/hrdq.21187

Scaufeli, W. B., \& Bakker, A. B. (2010). Defining and measuring work engagement: bringing clarity to the concept. In A. B. Bakker \& M. P. Leiter (Eds.), Work engagement: A handbook of essential theory and research (pp. 10-24). New York: Psychology Press.

Scaufeli, W. B., \& Bakker, A. B. (2004). Job demands, job resources and their relationship with burnout and engagement: A multi-sample study. Journal of Organizational Behaviour, 25, 293-315.

Schaufeli, W., \& Salanova, M. (2011). Work engagement: On how to better catch a slippery concept. European Journal of Work and Organizational Psychology, 20, $39-46$.

Schaufeli, W. B. (2014). What is engagement? In C. Truss, K. Alfes, R. Delbridge, A. Shantz, \& E. Soane (Eds.), Employee Engagement in Theory and Practice (pp. 15$35)$.

Schaufeli, W. B., Bakker, A. B., \& Salanova, M. (2006). The measurement of work engagement with a brief questionnaire: A cross-national study. Educational and Psychological Measurement, 66, 701-716.

Schaufeli, W. B., Salanova, M., Gonzalez-Roma, V., \& Bakker, A. B. (2002). The measurement of engagement and burnout: A two sample confirmatory factor analytic approach. Journal of Happiness Studies, 3, 71-92.
Seppalia, P., Mauno, S., Feldt, T., Hakanen, J., Kinnunen, U., Tolvanen, A. and Schaufeli, W. (2009). The construct validity of the Utrecht Work Engagement Scale:A multi-sample and longitudinal evidence. Journal of Happiness Studies, 3(10), 459-481.

Shuck, B. (2011). Integrative literature review: four emerging perspectives of employee engagement: an integrative literature review. Human Resource Development Review, 10, 304-328.

Shuck, B., Ghosh, R., Zigarmi, D., \& Nimon, K. (2013). The jingle jangle of employee engagement: Further exploration of the emerging construct \& implications for workplace learning and performance. Human Resource Development Review, 12(1), 11-35.

Shuck, B., Reio, T. G., \& \& Rocco, T. S. (2011). Employee engagement: an examination of antecedent and outcome variables. Human Resource Development International, 14(1), 427-445.

Shuck, B., \& Wollard, K. (2010). Employee engagement and ED: A seminal review of the foundations. Human Reource Development Journal, 9, 89-110.

Skinner, B. F. (1953). Science and Human Behaviour. New York: Free Press.

Sorenson, S. (2013). Employee engagement drives growth. Retrieved June 15, 2017, from http://www.gallup.com/businessjournal/163130/employee-engagement-drives-growth.aspx

Stander, M. W., \& Rothmann, S. (2010). Psychological empowerment, job insecurity andemployee engagement. South African Journal of Industrial Psychology, 36(1), $1-8$.

Towers Watson. (2013). Working today: Understanding what drives employee engagement. Retrieved May 23, 2017, from http:www.keepem.com/doc_files/Towers_Perrin_Talent_2013\%28TheFinal\%29.pdf

Viljevac, A., Cooper-Thomas, H. D., \& Saks, A. M. (2012). An investigation into the validity of two measures of Work Engagement. The International Journal of $\mathrm{Hu}-$ man Resource Management, 23(17), 3692-3709.

Wefald, A. J., \& Downey, R. G. (2009). Job engagement in organizations: fad, fashion, or folderol? Journal of Organizational Behavior, 30, 144-145.

Wefald, A. J., Mills, M. J., Smith, M. R., \& Downey, R. G. (2012). A Comparison of Three Job Engagement Measures: Examining their Factorial and Criterion-Related Validity. Applied Psychology: Health and WellBeing, 4, 67-90.

Witemeyer, H. A. (2013). Employee Engagement Construct and Instrument Validation. Georgia State University. Retrieved from http://scholarworks.gsu.edu/bus_admin_diss/17

Wollard, K. K., \& Shuck, B. (2011). Antecedents to employee engagement: a structured review of the literature. Advances in Developing Human Resources, 13(4), 429-446.

Wrzesniewski, A. (2003). Finding Positive Meaning in Work. In K. S. Cameron, J. E. Dutton, \& R. E. Quinn (Eds.), Positive Organizational Scholarship: Foundations of a New Discipline (pp. 296-308). San Francisco: Berrett-Koehler. 